Institute of $\mathbf{F}_{\text {ood and }} \mathbf{A}_{\text {gricultural }} \mathbf{S}_{\text {ciences }}$

\title{
Manual de los Reglamentos del Agua de Florida: Eliminación del Drenaje sobre el Sitio ${ }^{1}$
}

\author{
Michael T. Olexa, Laura Minton, Dulcy Miller, y Sarah Corbett ${ }^{2}$
}

\section{Agradecimientos}

Los autores agradecen a Richard Budell de la Oficina de Política del Agua Agrícola del Departamento de Agricultura y Servicios al Consumidor de Florida. Los autores también agradecen a David H. Hammonds, Consultor del Programa de Salud Ambiental, Oficina de Programas de Aguas de Drenaje en el Sitio, del Departamento de Salud de Florida, y a Edward A. Bettinger, Consultor del Programa de Salud Ambiental, Oficina de Programas de Agua del Departamento de Salud de Florida.

\section{¿Quien Regula la Eliminación del Drenaje sobre el Sitio?}

Mientras que los Estatutos de Florida contienen un conjunto de guías muy amplias para reglamentar la eliminación del drenaje, el Departamento de Salud (DDS) de Florida es la autoridad primaria para controlar las reglamentaciones especificas en todo el estado, sobre la instalación y uso de los sistemas de eliminación sobre el sitio.

No obstante, las reglas para la eliminación de desechos del Departamento de Protección Ambiental (DPA) serán aplicadas como sigue:

- el volumen estimado del drenaje domestico para ser procesado, excede a 10,000 galones por día.

1. Este es el documento EDIS FE087, una publicación del Department of Food and Resource Economics, Florida Cooperative Extension Service, Institute of Food and Agricultural Sciences, University of Florida, Gainesville, FL. Publicada Noviembre 2002. Por favor visite la página electrónica EDIS en http://edis.ifas.ufl.edu.

2. Michael T. Olexa, es profesor del Department of Food and Resource Economics, Florida Cooperative Extension Service, Institute of Food and Agricultural Sciences, University of Florida, Gainesville, FL; y miembro de Florida Bar; Presidente de Agricultural Law Committee of The Florida Bar; y Director del Agricultural Law Center. Laura Minton, Dulcy Miller, y Sarah Corbett son estudiantes graduadas de Levin College of Law, University of Florida, Gainesville, FL. Filiberto Reyes-Villanueva fue el traductor de la versión en ingles al español.

Esta publicación esta diseñada para proporcionar información precisa, actualizada y autorizada sobre esta material. Sin embargo, ya que las leyes, reglas administrativas y decisiones de la corte, sobre las cuales están basados, están sujetas a revisión constante; algunas partes de esta publicación podrían ser obsoletas en cualquier momento. Esta publicación es distribuida bajo el entendimiento que los autores no están involucrados en ninguna representación legal u otros servicios profesionales, y que la información contenida aquí no debe ser considerada como un substituto de una asesoria legal. Esta publicación no esta completa en proporcionar toda la información para lograr el cumplimiento de las leyes y reglamentos que gobiernan la protección del agua. Por estas razones, el uso de estos manuales por cualquier persona constituye un acuerdo para mantener libre de daño a los autores, al Florida Cooperative Extension Service, al Institute of Food and Agricultural Sciences, y a la University of Florida por cualquier demanda por responsabilidad de daños, o gastos en que pueda incurrir cualquier persona, como un resultado de hacer referencia o confianza sobre la información contenida en esta publicación. Esta publicación fue apoyada financieramente por el Florida Department of Agriculture and Consumer Services.

El Instituto de Alimentos y Ciencias Agrícolas es Un empleador que opera bajo Acción Afirmativa y provee Oportunidades Igualitarias, dedicado a promocionar la investigación, a información educativa y otros servicios, únicamente a los individuos e instituciones que operan baj discriminación sin considerar color, raza, sexo, edad, incapacidad u origen. Para más información sobre como obtener otras publicaciones de la extensión, comuníquese con la oficina de Servicio de Extensión de su condado. Servicio de Extensión de la Florida / Instituto de Alimentos y Ciencias Agrícolas / Universidad de la Florida / Christine Taylor Waddill, Decana. 
- el volumen estimado del drenaje comercial para ser procesado, excede de 5,000 galones por día.

- el agua contiene o contendrá desechos industriales peligrosos.

- el sistema esta localizado en un área que es zona para la industria o manufactura.

Si el sistema cae dentro de una de esas categorías, el DPA probablemente requerirá un permiso separado e impondrá restricciones adicionales sobre el sistema. Además, de las reglas estatales, los gobiernos locales tendrán típicamente sus propias reglas y requerimientos para permitir y regular el sistema de eliminación.

\section{¿Son Acceptables lo Sistemas de Drenaje sobre el Sitio?}

El estado no fomenta el uso de los sistemas de eliminación del drenaje (el cual, generalmente toma la forma de un tanque séptico y campos drenados).

Tanto los estatutos como las reglas del DDS requieren el uso de sistemas públicos o de inversionistas-propietarios en áreas donde ellos están disponibles.

A menos que el sistema este autorizado por la empresa y este siendo usado para eliminar solamente aguas grises, este debe estar conectado a un sistema de drenaje publico dentro de un año a partir de la fecha en que el sistema publico quedo disponible en el área.

Las aguas grises y aguas negras están definidas como sigue:

- Aguas grises es agua de desecho residencial de las bañeras, baños, lavabos, lavandería y lavaderos de cocina, excepto el desecho de estos últimos.

- Aguas negras es la parte del drenaje domestico expulsado de inodoros, urinarios y drenaje de la cocina.

\section{¿Dónde Deben Colocarse los Sistemas de Drenaje del Sitio?}

La ubicación del sistema es un factor clave para la determinación del daño potencial para el agua subterránea:

1. Es requerido que la ubicación de los campos de drenado deben estar a cinco pies de los cimientos de construcciones o líneas de propiedad, a 50 pies de los pozos de agua no potable y a 10 pies de la tubería de agua potable (a menos que las líneas estén cubiertas de concreto o doble tubo). Tampoco los campos de drene no pueden estar dentro de 15 pies de una desagüe pluvial.

2. Suelo recién rellenado o no usado es menos favorable para ubicar sistemas de desecho.

3. Estándares especiales se aplican para la ubicación de sistemas en suelos calizos, el cual es particularmente común en Florida.

Es también crucial, la zonificación para el uso de la tierra del área donde se va a instalar el sistema. Si un área es zonificada para industrias o manufacturas, el DDS monitoreará muy de cerca el sistema para asegurar que no recibe desechos tóxicos o peligrosos. Además, el sistema no será permitido si un sistemas de drenaje público esta disponible.

El tamaño del tanque y campo de drenado es también prescrito por las reglas, las cuales enlistan los tamaños mínimos de los tanques requeridos para cada tamaño de residencia u otro edificio. Las regulaciones del tamaño están basadas en la cantidad de desechos que estimara el DDS que generara cada tipo de edificio.

\section{¿Cómo debe ser Mantenido el Sistema?}

El dueño de una propiedad es responsable por el mantenimiento y buenas condiciones del sistema. Bajo las reglas del DDS, el propietario debe revisar el nivel del tanque como mínimo una vez cada tres años. Si basura triturada o drenaje comercial esta siendo descargada en el tanque, los dueños necesitan tener sus propios sistemas inspeccionados por un contratista con permiso para tanques sépticos o 
bombearlo una vez al año. Tanto los estatutos y las reglas prohíben el uso de solventes químicos orgánicos, químicos tóxicos o peligrosos, o productos del petróleo para remover la grasa del sistema. El sistema requiere un permiso del DDS, el cual requerirá de pruebas de que se ha usado el apropiado bombeo acarreo y técnica.

\section{¿Cuáles son los Procedimientos para el Abandono de un Tanque Séptico?}

Son requeridos un permiso y una cuota del DDS por el abandono de un tanque séptico, y deben seguirse los pasos:

- el tanque debe ser bombeado hacia fuera.

- el fondo debe ser abierto o roto para prevenir la retención de agua.

- el tanque debe ser rellenado con arena limpia o un material similar.

\section{¿Qué Permisos y Cuotas son Requeridos?}

El DDS requiere permisos para la instalación, reparación, alteración, modificación, reemplazo o abandono de todos los sistemas de eliminación de drenaje sobre el sitio. Antes de emitir un permiso, es requerida una aplicación y una investigación del sitio para todos los sitios por el DDS, llevada a cabo por ingenieros profesionales $u$ otras personas autorizadas por el estado de Florida. El DDS también requerirá de una inspección de todo el sistema séptico antes de ser enterrados.

El DDS se esforzara en ejecutar todas las inspecciones dentro de un día de trabajo después que haya sido notificado que la instalación del tanque esta completa. Debe pagarse una cuota por el permiso, la inspección y otros servicios necesarios llevados a cabo por el DDS. Generalmente las cuotas tienen una rango de $\$ 50$ a $\$ 200$. La cuota por la inspección y el permiso de un sistema residencial estándar es de alrededor de $\$ 50$.

Es esencial hacer notar que los gobiernos locales pueden tener requerimientos separados, incluyendo permisos separados (como permisos para plomería) que puedan ser mas estrictos que las reglas o leyes del estado.

\section{¿Cuáles son las Alternativas?}

Las reglas dan a los departamentos de salud publica de los condados individuales, la autoridad para aprobar sistemas alternativos en los sistemas sobre el sitio, como pilas, drenaje por gravedad, tubos de baja presión y otros sistemas, siempre que el condado perciba que no habrá efectos adversos. El DDS retiene la autoridad para aprobar el uso de medidas temporales tales como los inodoros portátiles. Las reglas de DDS también crea un Comité de Asesoria y Revisión de Variaciones, el cual escucha las peticiones de las variantes. La junta puede asesorar al DDS para permitir una variación cuando éste estime el cumplimiento indudablemente molesto para el aplicante. Sin embargo solamente el DDS tiene la autoridad para permitir una variación.

\section{Fuentes}

Estatutos de Florida sección 381.0065; 64E-6, Código Administrativo de Florida.

\section{Contactos de Información}

\author{
S-5, S-2
}

